\title{
Engaging Adult Learners of English Using Collaboration and Negotiation
}

\author{
Larcy C. Abello (Corresponding Author) \\ Department of Humanities, College of Arts and Sciences \\ University of the Philippines Los Baños, College, Laguna 4031 Philippines \\ E-mail: larcya@yahoo.com
}

Received: August 27, 2015 Accepted: September 9, 2015 Published: September 23, 2015

doi:10.5296/jet.v3i1.8351 URL: http://dx.doi.org/10.5296/jet.v3i1.8351

\begin{abstract}
This work stems from the author's experience as a teacher-researcher handling Intensive English for Foreign Graduate Students from several Southeast Asian countries, in line with the program of the University of the Philippines at Los Baños to enrich their reading and vocabulary skills.

This reports the teaching-learning practices which help learners to cope with their reading and vocabulary difficulties. Survey and interview encourage adult learners to take active part in planning targets based on identified needs. For these adult learners of English to be responsive and receptive, a thorough needs analysis is required to adopt an appropriate teaching-learning design. Contrary to a common practice of using a predetermined content and conduct of lessons provided by commercially available texts, this particular procedure encourages a contextualized and integrated approach and focuses on scaffolding and empowering of learners through a more dynamic and looser organization of subject matter. Collaboration and negotiation empower learners, making learning fulfilling and liberating; thus, the teacher acts as an effective facilitator of a learning process and not a mere lecturer/proctor who delivers a predetermined learning package.

The experience highlights the need for teachers to become active, flexible, and engaged action researchers to upgrade the quality of teaching and learning. No educator should settle doing the same routine (lessons, activities, exercises, approaches) considering the ever-changing role of English language in the globalized world. In short, an action research keeps the teacher on track as $\mathrm{s} /$ he remains faithful to the ultimate aim of English language teaching: that is, to produce autonomous and empowered individuals who can communicate effectively, solve problems strategically, and think/analyze critically.
\end{abstract}

Keywords: Adult learners, collaboration, negotiation, autonomous learning 


\section{Introduction}

Have you ever felt frustrated when everything seems dull inside your classroom? Have you found yourself wondering why most students never show interest or excitement working on their activities and exercises? This is exactly how you will feel if you miss to read your context of situation. This particular concern refers to the author's experience handling classes in reading and vocabulary development among foreign graduate students from different Southeast Asian countries pursuing their respective courses in the university.

This paper maintains that contrary to the usual practice of knowledge delivery in reading and vocabulary development consisting of predetermined content and conduct of lessons culled from commercially available materials and/or completion of worksheets that test separate skills, this procedure rationalizes the need for contextualized and integrated approach to scaffold learning and empower learners through a more dynamic and looser organization of topics, texts, and tasks. This starts with collaboration and negotiation between and among teacher and students as one community of learners.

After all, the learners are graduate students sent by their respective countries to pursue further studies in their field of expertise in the university. Knowles (1980) contends that the classroom climate should be one of "adultness", both physically and psychologically. In an "adult" classroom, adults "feel accepted, respected, and supported", further, there exists a "spirit of mutuality between teachers and students as joint inquirers" (p.47). Adults are capable of directing, or at least assisting, in planning their own learning. This capability to engage in autonomous learning and independent decision making encourages a teacher to mobilize and lead a group where, according to Tayao (2010), s/he functions as a coach to guide, monitor, and design different tasks that will be participative, enriching, relevant, and interesting.

\subsection{Rationale for the course offering}

For university students to be well-equipped as they go through rigorous and demanding academic endeavours, vocabulary knowledge and reading comprehension need attention.

The greater the learner's vocabulary, the less cognitive demands are placed on a learner since highly developed vocabulary facilitates effortless reading (Segalowitz \& Segalowitz,1993; Segalowitz, Segalowitz, \& Woods, 1998 cited in Roche \& Harrington, 2013) and result in better performance on comprehension tests (Chen, 2011; Miller \& Peleg, 2010; Nassaji, 2003; Qian, 1999 cited in Roche \& Harrington, 2013).

Moreover, there is no doubt about the claim of Coxhead, Newton and Webb (2014) when they declare in a panel discussion that, "without grammar little can be conveyed; without vocabulary nothing can be communicated."

\subsection{Needs analysis and course planning}

Initial inventory of learner needs and teacher expectations sets the pace in conducting a reading and vocabulary development class. Using survey and interview as instruments, pertinent data are gathered from the respondents to explore and describe the learning 
demands and consequently devise appropriate teaching-learning strategies. This procedure assures that uniqueness of every class is taken into account, as there is no universal formula that will work for all contexts.

1) Through an assessment of needs and participative discussions, everyone takes active part in the formulation and execution of learning goals and strategies with respect to the concerned learners. Collaboration and negotiation are the keys to motivate students, arouse their interests, and help them focus their attention on issues that matter.

2) Inasmuch as the foreign graduate students recognize their need to develop reading and vocabulary skills to cope with the course requirement in the university, the course design emphasizes reading-writing connection, meaning the enhancement of critical reading and effective writing.

3) Based on profile and confirmation during the interview, the students clarify their purpose of study. They are mostly into science-oriented courses, economics, and agricultural extension fields hence their focus on expository and academic-technical type of reading materials.

4) Moreover, their profiles reveal that they belong to adult age group, 25-50 years old. Since they are mature learners, they should not be treated like adolescents. They have set certain learning preferences, academic tools, and practices that could be enriched or developed as the case demands.

5) Their reading interests rest on specific content-related books and materials relevant to their respective fields of study. Instead of books and magazines for recreation and relaxation, they devote time reading for information, so they could eventually write quality output, whether academic papers or other professional, work-related tasks.

\subsection{Course Core Descriptors}

After a thorough needs analysis done in close consultation and coordination with the learners, a core descriptor of the course summarized in Table 1 is adopted. While the listing spells out the competencies expected from the students, it is not a hard and fast rule that cannot be adjusted to suit their skills. It simply serves as a helpful benchmarking guide for both the teacher and students to observe progress in the different reading and writing activities.

Table 1. Core Descriptors of the Course

\begin{tabular}{|l|l|}
\hline \multicolumn{1}{|c|}{ Reading } & \multicolumn{1}{c|}{ Writing } \\
\hline $\begin{array}{l}\text { Extract information from different text types with } \\
\text { accuracy and efficiency }\end{array}$ & $\begin{array}{l}\text { Present information using visual } \\
\text { organizer and information map }\end{array}$ \\
\hline Identify the information structure of a text & Construct a topic outline \\
\hline Identify topic sentences and supporting ideas & Write a summary \\
\hline $\begin{array}{l}\text { Determine validity of assertions, adequacy of evidence } \\
\text { and effectiveness of devices used by the author }\end{array}$ & Write a reaction paper \\
\hline Identify gaps and loopholes & $\begin{array}{l}\text { Write/propose to offer new } \\
\text { insights/alternatives }\end{array}$ \\
\hline
\end{tabular}

Reading-Writing Connection; Learning Competencies 


\section{Adult Learners}

What makes adult learners different? What constitutes adult learning? Would it require distinct teaching techniques to facilitate successful adult learning? Based on the extensive research of Brundage and Macheracher (1980 cited in Nunan, 2009, p.15), there are certain principles to guide adult learning, and some of them are the following:

1) Adults learn best when they are involved in developing learning goals for themselves that are matched with their self-concept.

2) Adults have already developed organized ways of focusing on, taking in, and processing information (cognitive style).

3) The learner reacts to all experience as $\mathrm{s} /$ he perceives it, not as the teacher presents it.

4) Adults enter into learning activities with an organized set of descriptions and feelings about themselves that influences the learning process.

5) Adults do not learn when over stimulated or when experiencing extreme stress or anxiety.

6) Adults learn best when the content is personally relevant to past experience or present concerns and the learning process is relevant to life experiences.

In view of the above-mentioned research finding, there is a great deal of information that reveals guidance for teachers to avoid conflicts and ensure a smooth delivery of knowledge and skills in class. Hilles and Sutton (2006) inform that dealing with adult learners may pose various problems such as psychological vulnerability, uncertainty, shame, competence, and attitudes. In addition, Rymes and Pash (2000) contend that learning interference may occur because students can preoccupy themselves with pretending they are engaged in learning, even if in reality they are not.

Having such a situation, soliciting collaboration of learners may encourage integration of perspectives and experiences (Rymes,1996), leading to cooperative effort in the formulation of learning objectives to address identified needs, for adult learners are capable of independent work and discovery learning (Grow, 1999). With life-long learning in mind, teaching thrusts must be directed toward developing autonomous learners.

\section{Autonomous Learning}

Autonomous learning promotes learner control over one's learning. Because learners are motivated to develop awareness and be able to design their learning objectives and paths, they are stimulated to participate actively in the learning processes to meet their needs, interests, and preferences. They act independently, yet collaborate and negotiate with the teacher and other classmates to reflect on their learning and find ways to improve it.

Since central to autonomous learning are student-centeredness and "the ability to take charge of one's own learning" (Holec, 1981, p.3 ), the teacher's responsibility is not more on teaching and explaining but on assisting students in the learning process (Farrell, 2013). Educators need to devise ways by which they can develop awareness among students, so they can be in control of their own learning. The teachers can employ explicit instruction 
framework, in which following these steps can be used: introduction/explanation — modeling — guided practice — independent learning.

According to Benson and Voller (1997) cited in Farrell (2013), once autonomy has been developed, students can employ it in at least five ways: for situations in which they study completely on their own; as a set of skills that can be learned and used in self-directed learning; as a means of navigating a constraining educational system; to take responsibility of their own learning; and for the right to decide the direction of their own learning.

However, it is accepted that there are two things that must be considered to pave the way for autonomy; one, although all students are able to learn autonomously with guidance and training, some of the higher order cognitive skills associated with autonomy are more appropriate for mature learners (Farrell, 2013), and two, when the practice runs counter to the native culture of learners, concepts and strategies should be employed slowly and methodically (Little, 2003; Gremmo \& Riley, 1995 cited in Farrell, 2013).

\section{Collaboration and Negotiation}

Benson and Huang (2008 cited in Farrell, 2013) claim that many younger students and those fresh to English lack the capacity to direct their own foreign language learning, at least in the early stages; hence putting more responsibility on the professors and instructors.

Unlike those younger students, these foreign graduate students are qualified to engage in collaboration and negotiation concerning decision making in areas like setting of learning goals, choice of topics, texts, and tasks and even in identifying/judging the degree of difficulty of materials. Aside from being mature, they also have a background to use English in communication, for they have been exposed to it from their English classes in their respective native countries. They may have some sort of inadequacy in language performance, but they have linguistic competence that the teacher can utilize to design activities that will put their linguistic knowledge into good, functional use. Explicit instruction framework can start with orientation through explanation, modelling of the task, guidance to practice, and finally allowing them to work independently.

Good teaching and learning can be attained when there is freedom and flexibility allowed to teachers and students to plan together and scaffold the teaching-learning process of reading and vocabulary development.

Learners' felt and real needs must be prioritized as the learners articulate them in their self-evaluation. The teacher, on the other hand, considers their proficiency level, aptitude and learning styles as $\mathrm{s}$ /he designs different tasks attuned to their proficiency in the target language, as these factors, according to Tayao (2010) determine to a large extent their success in carrying out different tasks.

In the end, what gets taught and how it is learned are arrived at through discussion, sharing and partnership. This will therefore, temper the conflict between what the teacher wants to teach and what the students want to learn.

\section{Collaborative and Negotiated Teaching-Learning Design}

The experience in handling a class of adult learners provides significant background that can help other educators. Instead of the teacher solely mapping out all the targets which include formulating the objectives, deciding on specific skills to be honed, choosing the reading texts, 
and selecting the activities to attain learning objectives, a community of learners composed of the teacher as facilitator and students engage in a collaborative effort to arrive at a negotiated teaching-learning plan.

The resulting course core descriptors serve as a general guide, yet the learning materials/texts are contributed by all the members of the study group. The teacher guides, coaches, and monitors while the learners interact, connect, and participate in doing various tasks. The collaborative procedure assures no one among the members is left out or unheard. It is both learner and learning- centered as each student gets to appreciate the value of language in reading and writing without feeling inadequate or inferior. Confidence and self-worth inspire them to persevere in a cooperative atmosphere.

The strategy is actually supportive of the basic principles of lesson planning since according to Jensen (2006), coherence, variety, and flexibility are useful to connect and form beneficial learning experience. Coherence means lessons hang together and not just a sequence of discrete activities. Variety in terms of topics, language, and skills prevents boredom and fatigue while flexibility means that plans are not meant to bind teacher and learners to preordained targets.

However, it must be clarified that the approach is consultative, and must not be interpreted as the teacher losing control of her class, or a case of student superiority over teacher's authority. It is not a one-sided, one-way mode of teaching and learning, rather an interactive, learning and learner-centered, communicative manner of class management. It must be stressed that adult learners possess critical thinking, problem solving, and decision making skills which necessitates a paradigm shift in the manner of knowledge delivery.

\subsection{Steps in Collaboration and Negotiation}

Gleaning from the writer's findings, here are some practical measures that will engage learners in their course of study.

Step 1-Clarify the teaching-learning objectives. Though the other language macro skill are not overlooked, stress must be given to the receptive-productive connection, specifically, the use of writing to assess reading comprehension (reading-writing connection). A clear expression of objectives directs learners toward smooth accomplishment of goals.

Step 2- Solicit the learning objectives of the learners. Even if English is a second or foreign language of the learner, the fact remains that using it in listening, speaking, reading, and writing is important in university education. Having this in mind, the choice of materials, texts, and tasks will point to realization of a clear learning objective; that is, the improvement of reading and vocabulary to excel in a chosen field of study.

Step 3-Identify the learning styles and strategies of students. The teaching strategies should match the learning repertoire of students. Using approaches that are contrary to students' perceptions of which methods work for them or not will be an exercise in futility as they will not bring good results. In this particular case, the learners prefer group discussion whether in dyads, triads or small groups; close reading of texts; writing in reaction to a reading 
experience; and oral and written exercises that put to test decision making and problem solving. These strategies hone their craft in asserting and arguing which lead to better comprehension.

Step 4-Assess the reading attitudes. Imposing the reading materials to be studied interferes with student interests. Since their choice depends on specific area of study, there is lesser problem with regard to vocabulary and schema building is not burdensome. Motivation inspires reading speed and comprehension. Expository texts with TRI (topic-restriction-illustration) and PSn (problem-solution) macrostructure appeal to them instead of literary texts.

Step 5- Encourage decision making, problem solving, and critical thinking on making choices. Practice in using these skills help to create a contextualized and integrated approach to learning that is rooted from a dynamic and looser organization of lessons. This ensures connection of activities inside and outside the confines of the classroom that will eventually produce motivated, focused, and driven students.

Step 6- Motivate students to work with peers and treat the teacher as a member of a community of learners. The teacher can inspire and model the behaviour, using small group discussions, communicative language and task-based language activities to support autonomous learning and show the value of collaboration and negotiation in meaning-making process. A strong community of learners enforces positive atmosphere characterized by productive partnership of people involved in and guided with a similar purpose of helping one another within a unified management of learning.

\subsection{Additional Pointers: Meaning-Oriented Instruction}

At this point, it is worth mentioning that the measures employed in collaboration and negotiation to engage learners in reading and vocabulary development is in consonance with meaning-oriented instruction as opposed to the usual transmission of information. According to Williams (1995 cited in Assassfeh, Khwaileh, Al-Shaboul \& Alshboul, 2012), " meaning-oriented instruction aims at developing the language learners' communicative competence through paying close attention to authentic language use, encouraging learner-learner and peer-peer negotiation of meaning, encouraging learners' risk taking, focus on fluency, which entails emphasis on language production rather than correctness, and assigning importance to learners' autonomy" (p. 526). Further, Savignon (2007, cited in Assassfeh et al., 2012) clarifies that "MOI is not limited to face to face communication, nor is it confound to oral communication; it applies to reading and writing as well, as long as learners are involved in meaning expression, interpretation and negotiation"(p. 526).

\section{Conclusion}

Have you ever thought of how influential teachers are in defining ways to treat adult learners; in formulating feasible, sustainable, context-sensitive plans for classes in reading and vocabulary development; and in articulating a teaching philosophy that will make a big difference in learners' lives? 
By clarifying the teaching objectives, an achievable pace for an enriching class is set. By soliciting students' learning objectives, active participants in knowledge exploration journey are invited. By identifying learning styles and strategies, individual differences are recognized and respected. By assessing reading attitudes, meaningful reading experiences are provided. By encouraging decision making, problem solving and critical thinking, self-directed, life-long learners are developed. By motivating students to join a community of learners, a strong statement is declared; that is, through collaboration and negotiation, adult learners of English gain empowerment and autonomy, which will equip them wherever they go and whatever goals they pursue.

The time has come for teachers to do introspection and retrospection, a chance to decide whether to be proactive or reactive. To be active, flexible, and reflective action researcher will lead to upgrading quality of teaching and learning. It is imperative to look into power relations, or even the preference for transmission instead of transaction-transformation view of learning considering the ever-changing role of English in the globalized world.

A reading and vocabulary development class can serve as a good venue where varied and many experiences may offer worthy and apt opportunities for students to learn as they listen, speak, read, write, view, and observe. Questions provoke thinking. Dynamic discussions and conversations bring out insights and realizations based upon expressions of opinions, beliefs, ideas, and values. A class in reading and vocabulary development does not have to be plain, simple or even boring. It could be fun, challenging and fulfilling.

\section{References}

Abello, L. C. (2014). Collaboration and negotiation: Scaffolding and empowering adult learners of English. Conference Proceedings of the 12th Asia TEFL and 23rd MELTA Internatioal Conference. Borneo Convention Center, Kuching, Sarawak, Malaysia. August 28-30.

Assassfeh, S. M., Khwaileh, F. M., Al-Shaboul, Y. M., \& Alshboul, S. S. (2012). Communicative language teaching in an ELF context: Learners' attitudes and perceived implementation. Journal of Language Teaching and Research, 3(3), 525-535.

Coxhead, A., Newton, J., \& Webb, S. (2014). Developing an effective vocabulary learning program. Featured Panel at the $12^{\text {th }}$ Asia TEFL and $23^{\text {rd }}$ MELTA International Conference, Borneo Convention Center, Kuching, Sarawak, Malaysia. August 28-30.

Farrell, G. (2013). Autonomous language learning. The English Connection, 17(1), 8-9.

Grow, G. (1999). Staged self-directed learning. Journal of Adult Literacy, 44(2), 104-114.

Hilles, S., \& Sutton, A. (2006). Teaching adults. In M. Celce-Murcia (Ed.), Teaching English as Second or Foreign Language. USA: Heile\&Heinle, Thomson Learning Asia.

Jensen, L. (2006). Planning lessons. In M. Celce-Murcia (Ed.), Teaching English as Second or Foreign Language. USA: Heinle\&Heinle, Thomson Learning Asia.

Knowles, M. S. (1980). The modern practice of adult education: From pedagogy to 


\section{Macrothink}

andragogy. New York: Cambridge Books.

Nunan, D. (2009). Second language teaching and learning. Singapore: Cengage Learning Asia.

Roche, T., \& Harrington, M. (2013). Recognition Vocabulary Knowledge as a Predictor of Academic Performance in an English as a Foreign Language Setting. Language Testing in Asia, 3, 12. http://wwwlanguagetestingasia.com/content/3/1/12

Rymes, B. (1997). Second language socialization: A new approach to second language acquisition research. Journal of Intensive English Studies, 11, 143-155.

Rymes, B., \& Pash, D. (2000). Questioning identity. The case of one second language learner. Paper presented at the American Association for Applied Linguistics Annual Conference. Vancouver, Canada.

Savignon, S. J. (2007). Beyond communicative language teaching: What's ahead? Journal of Pragmatics, 39, 207-220.

Tayao, M. L. G. (2010). A new look at the multi-faceted roles of a language teacher with focus on the teacher as a strategy coach. Plenary Session at PALT $50^{\text {th }}$ Anniversary and $6^{\text {th }}$ International Confrence. SOLAIR, University of the Philippines Diliman, Quezon City. December 2-3.

\section{Copyright Disclaimer}

Copyright reserved by the author(s).

This article is an open-access article distributed under the terms and conditions of the Creative Commons Attribution license (http://creativecommons.org/licenses/by/3.0/). 